\title{
A HISTÓRIA DA FAMÍLIA COMO UM CAMPO PLURAL DE COMPREENSÕES E DE POSSIBILIDADES NA COMARCA DO RIO DAS VELHAS NO SÉCULO XVIII
}

\author{
Igor Bruno Cavalcante dos Santos ${ }^{1}$
}

\begin{abstract}
Resumo: O presente artigo é fruto de reflexões mais amplas realizadas em pesquisas anteriores, propondo (re)pensar a história da família enquanto um objeto de estudo passível de ter a sua noção e seus sentidos ampliados, não permitindo, portanto, o invólucro homogêneo ao qual fora relegado por muitos anos entre estudiosos que a analisaram pelo viés de discursos oficiais. Para tanto, utiliza-se as devassas eclesiástica como fontes principais e, por meio dessa documentação, investiga-se a prática do concubinato na Comarca do Rio das Velhas enquanto uma relação conjugal capaz de ser inserida no campo da ilegitimidade e enquanto uma forma simultânea de conjugalidade instituída consuetudinariamente.
\end{abstract}

Palavras-chave: Família. Concubinato. Historiografia.

\section{THE HISTORY OF THE FAMILY AS A PLURAL FIELD OF UNDERSTANDING AND POSSIBILITIES IN THE $18^{\text {TH }}$ CENTURY RIO DAS VELHAS COUNTY}

\begin{abstract}
The present article is a proposal which results the broader reflections on previous research, about how to (re) think a family history as an object of study that can provide some notion and expansion of sense, thus not allowing a homogeneous envelope, which has been relegated for many years among scholars who have analyzed it through official speeches. For such, they have been using ecclesiastical debauchery as the main source, and started from these documentations for searching about concubinage in Rio das Velhas Country, bringing that as a relationship capable of being inserted in the field of illegitimacy and as a simultaneous form of conjugality instituted customarily.
\end{abstract}

Keywords: Family. Concubinage. Historiography.

\section{L'HISTOIRE FAMILIALE COMME UN GRAND CHAMP D'ENTENTE ET DE POSSIBILITÉS DANS LA RIVIÈRE 18E SIÈCLE DE LA VIEILLE RIVIÈRE}

Résumé: Cet article est une proposition, fruit de réflexions plus larges menées lors de recherches antérieures, visant à (re) penser l'histoire de la famille comme un objet d'étude capable d'en élargir la notion et les sens, ne permettant ainsi le boîtier homogène auquel il a été relégué pendant de nombreuses années parmi les érudits qui l'ont analysé à travers des discours officiels. Pour cela, la pauvreté ecclésiastique est utilisée comme source principale et, à travers cette documentation, la pratique du concubinage dans le comté de Rio das Velhas est étudiée en tant que relation conjugale susceptible d'être insérée dans le domaine de l'illégitimité et en tant que forme simultanée de conjugalité. institué habituellement.

Mots-clés: Famille. Concubiner. Historiographie.

\footnotetext{
${ }^{1}$ Professor de História e coordenador pedagógico na Rede de Ensino Gênesis. Graduou-se em História (Bacharelado e Licenciatura) pelo Centro Universitário de Belo Horizonte (UNI-BH) em 2012. Tornou-se Mestre em História pela Universidade Federal de Ouro Preto (UFOP) em 2017 e, atualmente, desenvolve suas pesquisas de doutorado em História na mesma instituição.
}

Revista Escritas do Tempo - v. 1, n. 3, nov/2019-fev/2020 - p. 247-269 


\section{LA HISTORIA DE LA FAMILIA COMO UN CAMPO PLURAL DE ENTENDIMIENTOS Y POSIBILIDADES EN LA REGIÓN DE RIO DAS VELHAS EN EL SIGLO XVIII}

Resumen: Este artículo es una propuesta, el resultado de reflexiones más amplias llevadas a cabo en investigaciones anteriores, para (re) pensar la historia familiar como un objeto de estudio capaz de expandir su noción y sus sentidos, lo que no permite la carcasa homogénea a la que había sido relegado durante muchos años entre los estudiosos que lo analizaron a través de discursos oficiales. Para esto, la falta de sentido eclesiástico se utiliza como fuente principal y, a través de esta documentación, se investiga la práctica del concubinato en el condado de Rio das Velhas como una relación conyugal capaz de insertarse en el campo de la ilegitimidad y como una forma simultánea de conyugalidad. instituido habitualmente.

Palabras llave: familia; concubinado; historiografía.

\section{Introdução}

Em história, podemos dizer que as generalizações possíveis, isto é, aquelas que conseguiriam enquadrar determinados contextos menores noutros mais amplos são, ou deveriam ser, raras. No mínimo, para garantir a nossa margem de segurança frente aos desafios situados nas complexas dinâmicas do cotidiano, poderíamos defender que essa afirmação inicial se situa no campo do que se considera recomendável: aquele em que, havendo menos generalizações, tenderíamos, consequentemente, a maiores chances de se compreender e buscar as especificidades das ações humanas e, a partir daí, situá-las e articulá-las a outras relações com implicações coletivas e, se possível, conectadas ${ }^{2}$.

Essa ideia que sai em defesa do particular quando tratamos dos contextos e eventos que caracterizam a História se deve ao fato de que os chamados sujeitos ou agentes históricos têm como características intrínsecas a particularidade e a subjetividade que se apresentam enquanto resultados de especificidades constitutivas. No entanto, entre esse reduzido, perigoso e quase execrável campo das generalizações prováveis, poderíamos enquadrar a "família" como instituição histórica.

Em outras palavras, não temendo as arriscadas generalizações em História, podemos afirmar, com pouca margem para dúvidas, que a família teria existido em todas as sociedades que se têm notícias. Não obstante, como já fora dito, as maneiras de

\footnotetext{
${ }^{2} \mathrm{Na}$ década de 1970 os estudos que surgiram com esta característica e proposta, a de se pensar o microcosmo social em detrimento do macrocosmo, recebera o nome de "micro-história". Autores como o francês Emmanuel Le Roy Ladurie e o italiano Carlo Ginzburg com os seus estudos "Montaillou" (1975) e "O queijo e os vermes" (1976), respectivamente, deram início à proposta de uma história que surgia com a premissa de pensar o indivíduo ou uma comunidade em específico e, a partir daí, compreendê-los num contexto maior. As críticas a essa proposta metodológica foram inúmeras, tanto favoráveis (de um público geral) quanto contrárias (sobretudo de alguns historiadores profissionais da época). Para um panorama acerca da chamada "micro-história", bem como de suas implicações e críticas, ver, dentre outros, Burke (2002). Ler, especialmente, o capítulo 2, "Modelos e métodos", p. 39-66.
}

Revista Escritas do Tempo - v. 1, n. 3, nov/2019-fev/2020 - p. 247-269 
organização humanas são variadas e se destacam pelas particularidades que as constituem, o que, forçosamente, leva também o sentido e a noção de família ao lugar das incertezas e das distintas e múltiplas possibilidades.

Esse objeto de estudo, situado entre o particular (pela polissemia, como veremos) e o geral (no sentido de existir em todas as sociedades), viabiliza o tropeço do estudioso menos atento às dinâmicas que são responsáveis pelas formas variadas de se pensar as constituições dessa instituição no contexto de determinada sociedade. Contudo, e ao mesmo tempo, permite olhares distintos de áreas igualmente variadas acerca da temática, o que vem ocorrendo há muitos anos entre os especialistas de modo geral.

Em grande parte, enquadrando-se no campo de interesse de historiadores, a história da família tem sido estudada, sobretudo, por meio das documentações eclesiásticas, elaboradas pela Igreja Católica através de seus representantes, e de outras fontes de caráter mais burocrático e administrativo, elaboradas pelo Estado metropolitano ${ }^{3}$. Os arquivos eclesiásticos guardam um tipo de fonte documental que atendeu, no passado, a interesses específicos de tentativas (muitas vezes frustradas) de moralismo e de controle, e que atende, no presente, aos estudiosos preocupados em compreender traços representativos dos costumes da sociedade que viveu na América portuguesa.

No período colonial, ter acesso às práticas que constituíam fatos e eventos marcantes do dia a dia da população, como nascimento, casamento e morte, por exemplo, os assim também chamados "ritos de passagem", dariam à Igreja um poder de controle físico e psicológico muito almejado para que se pudesse implantar, no território e nas gentes que habitavam essa possessão portuguesa, os valores éticos e morais considerados ideais para os "bons cristãos". Além desses ritos de passagem, que a Igreja buscou padronizar com os registros, outras demandas do cotidiano, como costumes que se criavam e/ou se reproduziam e que eram monitorados pelo clero por serem considerados desviantes, também se constituíram em pautas importantes para a Igreja e ocuparam muito do tempo dos eclesiásticos em arraiais, vilas e cidades coloniais.

Para os casos já citados, de nascimentos, casamentos e mortes, eventos que se situavam dentro da normalidade prevista pela Igreja, eram elaborados por esta os registros que oficializavam tais acontecimentos. No que diz respeito aos costumes de

\footnotetext{
${ }^{3}$ Vale destacar, aqui, que, em função do padroado e da união entre Estado e Igreja, muitos documentos que eram elaborados pela igreja católica, possuíam caráter jurídico também.
} 
outros fatos e eventos que se enquadravam fora dos critérios considerados ideais pelo clero, os seus registros atendiam a outros propósitos, mais pedagógicos e de cunho moralista. Nesse contexto, situavam-se as chamadas devassas eclesiásticas, documentação a partir da qual é possível compreender mais e melhor os aspectos rotineiros da sociedade colonial ${ }^{4}$. Eram nesses documentos que se registravam os chamados "crimes de costumes", dentre eles, sendo o principal, o mais registrado e o mais perseguido e reprimido, o concubinato, que era um tipo de união conjugal situado fora dos enlaces matrimoniais ${ }^{5}$.

Não é nosso propósito, neste artigo, discorrer acerca das tipologias e/ou lógicas constitutivas dos concubinatos. Aqui, temos como intento ampliar a noção de família, enquadrando a prática conjugal da mancebia como uma de suas definições possíveis. Entretanto, essa ressalva se justifica pelo fato de, em nosso entendimento, não ser possível, para se pensar uma ampliação do conceito e noção de família, deixar as relações concubinárias de $\operatorname{lado}^{6} \mathrm{ou}$, tampouco, dar a elas o tratamento que muitos já lhes deram outrora, o de relações marginais ${ }^{7}$.

No que diz respeito à outra documentação, elaborada pelo Estado metropolitano e de caráter mais burocrático e administrativo, fora elaborada no contexto de formação e melhoramento das formas de funcionamento do Estado moderno, especificamente na produção de fontes documentais. A sua contribuição se deu com a própria burocratização da prática administrativa e com a otimização dos princípios referentes ao fisco. Esse processo favoreceu a produção de listagens nominais de habitantes, ou mapeamentos populacionais por fogos (também denominados "maços de população"), cujos fins variados (fiscais, militares, dentre outros) permitiram aos estudiosos compreender melhor o interior dos domicílios, conhecendo, portanto, suas conformações e configurações.

É por meio desse corpus documental que os estudiosos da História da Família vêm, desde os últimos 30/40 anos, rastreando e analisando as intrincadas tramas do

\footnotetext{
${ }^{4}$ Ver, sobre isso, dentre outros, em SOUZA, 1999; VIANA, 2017.

5 A historiografia que se dedica às relações concubinárias é extensa. Ver, dentre muitos outros, em LONDOÑO, 1999, OLIVEIRA, 1999; CERCEAU NETTO, 2008; 2017; SANTOS, 2018.

${ }^{6}$ Sobre alguns outros estudos que compreendem o concubinato como uma possibilidade alternativa de conjugalidade, situada no campo da ilegitimidade, mas largamente difundida entre os costumes, ver em FIGUEIREDO, 1997; 1999; LONDOÑO, 1999; PAIVA, 2001; 2009; FURTADO, 2003; CERCEAU NETTO, 2008; 2017; SANTOS, 2018.

${ }^{7}$ Sobre alguns autores que abordaram o concubinato situando-o no campo da marginalidade, ou enquanto relações pertencentes aos ditos "desregramentos sexuais", ver, dentre outros, em VAINFAS, 2010; VILLALTA, 1993; SAMARA, 1986.
} 
cotidiano por meio das quais ocorreram as formações e formatações múltiplas dessa instituição que, em última instância, como dito, acompanha todo o processo de formação de qualquer sociedade. Considerando que cada uma dessas fontes possui uma tipologia, uma forma de se estruturar e uma lógica peculiar - desde a elaboração do documento, perpassando por princípios distintos que envolvem interesses e formas de poder, à própria disponibilidade de tais fontes -, os estudiosos buscam ampliar os seus conhecimentos envolvendo as configurações familiares em suas mais variadas nuances e isso, nos últimos anos, tem viabilizado o alargamento da própria noção de família ${ }^{8}$.

Nos dias atuais, referente às abordagens acerca da América portuguesa, o estudo da família vem contribuindo significativamente para a ampliação da compreensão a respeito dos diversos aspectos que constituíram a complexa sociedade colonial. Dentro desse campo de investigação, as tramas do cotidiano são esmiuçadas e as distintas maneiras de pensar e formas de viver dão sons, cores e contornos a uma sociedade que se apresentou sob a forma de um verdadeiro caleidoscópio biológico e, principalmente, cultural.

É notável a produção cujo intento é atrelar temáticas que se mostram interligadas e que, analisadas conjuntamente, viabilizam esclarecimentos referentes à formação sociocultural da colônia. Entre os estudiosos brasileiros, desde o início de suas inquietações, alguns dos pontos marcantes em suas produções têm sido as constantes preocupações em torno da heterogeneidade da sociedade e do papel desempenhado pelas estruturas escravistas em sua conformação ${ }^{9}$. As maneiras pelas quais esses fatores exerceram influências nas configurações dos variados tipos de arranjos familiares construídos durante o período colonial também foram, e ainda são, decisivas para o estudo da História da Família de forma ampla. Contudo, como já mencionado, trata-se de uma noção polissêmica e que variou consideravelmente no tempo e em espaços diferentes.

\section{Família: alguns conceitos e noções para as Minas Setecentistas}

Na América portuguesa, dicionaristas como Raphael Bluteau e Antônio de Morais Silva já se propuseram a definir o conceito de família em inícios dos séculos

\footnotetext{
${ }^{8}$ Um breve panorama acerca da história da família brasileira, com suas características, formatações, problematizações conceituais, debates da historiografia, dentre outros aspectos, pode ser encontrado no livro “A família brasileira”, de autoria de Eni de Mesquita Samara. Ver: SAMARA, 1986.

${ }^{9}$ Sobre outros balanços historiográficos referentes à história da família, ver, dentre outros: FARIA, 1997; SCOTT, 2004, 2009, 2015.
} 
XVIII e XIX, respectivamente. Bluteau (1712, p. 28) ressaltava que o termo "família" abrangia as "pessoas de que se compõem uma casa; pais, filhos e domésticos". Através dessa passagem, pode ser percebido que, para o padre jesuíta setecentista, a noção de família perfazia a máxima de pessoas que, no mesmo domicílio, conviviam, isto é, viviam juntas.

Morais Silva (1813), ampliando a definição de Raphael Bluteau, acrescentou que se tratava de "pessoas de que se compõe a casa, e mais propriamente as subordinadas aos chefes, ou pais de família”. Para Silva, além de a noção de família abarcar um grupo de pessoas que conviviam num mesmo espaço, tais membros deveriam se encontrar sob a responsabilidade e mando, deveriam encontrar-se "subordinadas", portanto, a um "chefe ou pai” de família ${ }^{10}$. Em ambos os casos é possível notar a ênfase e a prevalência da ideia de "gente da casa" para a construção de uma noção de "família". Ou seja, a coabitação é determinante para a noção a que se presta e, ao mesmo tempo, independe da consanguinidade e do parentesco, esse último dissociado do sentido atual ${ }^{11}$.

Se por um lado a noção proposta por Bluteau favorece a compreensão de "família" em um sentido amplo, dissociado de princípios de consanguinidade e parentesco, por outro, pode ser mais bem entendida se tomada como referência para se pensar a realidade das Minas Gerais no transcorrer do século XVIII, uma vez que a base familiar enquadrava-se numa formatação não apenas a cristã, considerada a forma legítima de união conjugal, mas esta dividia espaço com outras possibilidades validadas consuetudinariamente. Contribuição também possível de se verificar por meio da definição oferecida por Morais Silva, ainda que este amplie a percepção de família, pensando-a enquanto uma instituição dominada pela premissa de tempos antanho fundamentada no "pátrio poder", princípio que, inserido na tradição historiográfica, daria início às teorias em torno do chamado patriarcalismo ${ }^{12}$.

\footnotetext{
${ }^{10}$ Essa visão de Morais Silva, com o passar do tempo, e desconectada dos estudos regionais, deram condições à perpetuação de teorias que preconizavam o mito da submissão feminina, muito criticado a partir dos estudos revisionistas que se dedicaram a compreender a atuação das mulheres na sociedade colonial. Ver, dentre outros: FIGUEIREDO, 1999; ALGRANTI, 1993; PRIORE, 2009.

${ }^{11}$ Segundo o dicionário Aurélio Buarque de Holanda Ferreira em sua $4^{a}$ edição (2001, p. 515), "parente" pode ser compreendido como "pessoa que, em relação à outra(s), pertence à mesma família, quer pelo sangue, quer por casamento". Já a palavra "parentesco", enquanto derivação da primeira, tem a seguinte definição: "qualidade de parente. 2. Origem comum. 3. Traços comuns; conexão".

${ }^{12}$ Para o caso brasileiro, o pioneiro e o autor considerado mais clássico nessa perspectiva fora o sociólogo pernambucano Gilberto Freyre que, na década de 1930, publicara seu célebre "Casa grande e senzala". Cf. FREYRE, 2006. Na esteira de Freyre vieram outros estudos, tanto para criticar a visão de uma sociedade fundamentada no regime patriarcal quanto para corroborar essa premissa. Ver, dentre outros: CORREA, 1982; VAINFAS, 1989; BRÜGGER, 2007.
} 
Tomando esses dois autores como modelos referenciais para se pensar as noções de família na América portuguesa, encontramos a possibilidade de se problematizar os arranjos familiares constituídos na comarca do Rio das Velhas e que assumiram nítida e conscientemente o caráter de união ilegítima, porém comum e corriqueira.

\section{O concubinato como reflexo da pluralização da família colonial}

Sabe-se que a história ocidental se caracterizou pela existência de modelos múltiplos de organizações familiares. Por essa razão, conforme destacou Sheila de Castro Faria, "talvez o mais correto fosse a pluralização" do termo (FARIA, 1997, p. 242). Ou seja, para Faria, o mais adequado seria o emprego da palavra "famílias", no plural, e não em sua forma grafada no singular, "família", que atribui um sentido homogeneizante e demasiado fechado, formatado, impedindo, portanto, as distintas possibilidades constitutivas.

Em Minas Gerais colonial, como resultado de um intenso processo de misturas envolvendo povos com seus corpos e suas culturas, arranjos familiares diversificados foram construídos a partir de valores de referências indígenas, africanos, europeus e mesmo os que já se apresentavam enquanto resultado e resultante dessas misturas, aqui denominadas mestiçagens ${ }^{13}$.

Para se compreender o complexo mundo das tramas familiares engendradas no território mineiro e, por extensão, para toda a América portuguesa, bem como para ampliar a noção proposta por Bluteau e Silva, podemos utilizar esses mesmos autores noutros momentos. Bluteau, em outro verbete, esboçando o significado da palavra "familiaridade", argumenta que se tratava de uma "amizade particular dos que se frequentam, e muitas vezes andam juntos por amizade ou trato". Com esse conceito, o jesuíta retrata, ampliando, a noção de um fato que, no contexto mineiro, pode auxiliar na compreensão de um modelo de formatação familiar existente nas terras do ouro e das pedras preciosas, que fora a prática da mancebia em distintas matizes ${ }^{14}$.

Como há muito já vem se discutindo na historiografia especializada ${ }^{15}$, o concubinato fora um modelo de arranjo familiar de definição imprecisa. De acordo com

\footnotetext{
${ }^{13}$ Entende-se, neste artigo, o conceito de mestiçagem como o fizera o historiador francês Serge Gruzinski (2001, p. 62), Para este autor, mestiçagem pode ser entendida como misturas "entre seres humanos, imaginários e formas de vida, vindos de quatro continentes - América, Europa, África e Ásia".

${ }^{14}$ Em seu livro intitulado "Um em casa de outro", Rangel Cerceau Netto identificou, para a realidade mineira no setecentos, tipos distintos de concubinato. Sobre isso, ver: CERCEAU NETTO, 2008, p. 104114.

${ }^{15}$ Vide nota 4.
} 
o que definira as próprias Constituições Primeiras do Arcebispado da Bahia (1707), tratava-se de uma "ilícita conversação do homem com mulher continuada por tempo considerável" ". Como é possível perceber, o indicativo taxativo de "ilícita" já confere uma conotação de irregularidade, ou melhor, ilegitimidade, à conversação de um homem e uma mulher. Além disso, os próprios meios normativos da época traziam, podemos notar, uma imprecisão (característica dos corpos jurídicos normativos do Antigo Regime), quanto à definição de tal prática e, fazendo isso, atrelava essa inconsistência à concepção religiosa de matrimônio (modelo ideal, e única forma de união conjugal reconhecida pela Igreja Católica), atuando no sentido de restringir, ainda mais, as opções conjugais e outras variantes para enlaces afetivos das gentes da colônia.

Analisando a realidade da comarca do Rio das Velhas no século XVIII através do estudo das devassas eclesiásticas é possível perceber que as práticas concubinárias, além de terem constituído o topo das denúncias nos tribunais eclesiásticos, multiplicaram-se e constituíram-se na base, senão legal, ao menos costumeiramente aceitável, de se vivenciar relações afetivas, duradouras e estáveis.

Tabela 1: Tipos de delitos nas devassas eclesiásticas - Comarca do Rio das Velhas $(1727-1756)$

\begin{tabular}{|l|c|c|}
\hline & N. Absoluto & Porcentagem \% \\
\hline Concubinato & 986 & 91,1 \\
\hline Jogos de azar / Tavolagem & 8 & 0,7 \\
\hline Alcovitagem & 8 & 0,7 \\
\hline Consentidor & 8 & 0,7 \\
\hline $\begin{array}{l}\text { Não ouvir missa ou não observar preceitos } \\
\text { católicos }\end{array}$ & 18 & 1,7 \\
\hline Usura & 3 & 0,3 \\
\hline Práticas supersticiosas & 2 & 0,2 \\
\hline Galanteador & 1 & 0,1 \\
\hline Curandeiro & 11 & 1,0 \\
\hline Viver sem licença da mulher & 18 & 1,7 \\
\hline Mau costume, bebedeira, rueiro, linguagem vil & 9 & 0,8 \\
\hline Dar má condição de vida à mulher / marido & 5 & 0,5 \\
\hline Meretriz & 5 & 0,5 \\
\hline Total & 1082 & 100,0 \\
\hline
\end{tabular}

Fonte: AEAM e CEDIC-BH, Livros de Devassas Eclesiásticas entre 1727 - $1756 .{ }^{17}$

\footnotetext{
${ }^{16}$ Constituições Primeiras do Arcebispado da Bahia, Livro 5, Título XXII, 979.

${ }^{17}$ Esta tabela foi construída e, primeiramente, utilizada por Rangel Cerceau Netto em sua dissertação de mestrado, a posteriori publicada pela editora Annablume com o título “Um em casa de outro”, em 2008.
} 
O objetivo deste texto não é realizar uma análise pormenorizada das tipologias do concubinato, nem dos sujeitos envolvidos. Em pesquisas anteriores já o fizemos, inclusive analisando as uniões mistas e as compreendendo enquanto resultantes e resultados dos complexos processos de mestiçagens na América portuguesa. Aqui, nos detivemos tão somente a problematizar e diversificar a noção de família nas Minas Gerais, mormente por meio da historiografia mais recente.

Afirmamos, anteriormente, que as relações concubinárias se situavam no campo do que as devassas eclesiásticas registravam como "crimes de costumes". De acordo com a tabela reproduzida, é possível perceber que das 1082 denúncias de "delitos" realizadas no tribunal eclesiástico na comarca do Rio das Velhas, a mais populosa das Minas Gerais ${ }^{18}$ no setecentos, entre os anos de 1727 a 1756, contabilizou-se 986 delitos de concubinato, o que corresponde a $91,1 \%$ dos casos.

Outros estudiosos, em pesquisas que se dirigiram a regiões distintas, também identificaram a presença, com o destaque, das relações concubinárias em meio à população ${ }^{19}$. Como, recentemente, afirmara Rangel Cerceau Netto, "esse tipo de relação, durante o século XVIII, causava escândalo aos religiosos, mas era um tipo de relacionamento que servia aos interesses de mulheres e homens" (CERCEAU NETTO, 2017, p. 115).

Os estudiosos que têm se debruçado sobre as práticas daqueles que viviam “como se casados fossem", dito da época, destacam que tais uniões se apresentam como uma soma de fatores que vão desde a mistura entre modelos familiares distintos de povos que compuseram a complexidade sociocultural da colônia, tais como europeus, indígenas, africanos e mestiços, à própria possibilidade de mudanças, adaptações, ressignificações, dentre outros fatores que incidiram, inclusive, na própria variação interna desse tipo de conjugalidade. Considerando esse aspecto, nem mesmo as próprias relações de mancebia constituíram-se como conformações estáticas. Houve inúmeras possibilidades para a sua efetivação. Esse fato aproxima essas práticas tanto da noção de família (apesar de suas especificidades) quanto de familiaridade propostas por Bluteau e Silva.

Considerando essa afirmação, entende-se como válida a assertiva preconizada por Sheila de Castro Faria, em defesa de uma pluralização da noção de família em

\footnotetext{
${ }^{18}$ Para conferir outros estudos que também trabalham com essas estimativas, ver: MAXWELL, 2005, p. 300 .

${ }^{19}$ Ver, dentre outros: FIGUEIREDO, 1997; LONDOÑO, 1999; BRÜGGER, 2007.
} 
detrimento de sua singularidade. Isto é, uma vez mais, fica nítida a importância de ampliação do sentido e da noção de família por meio de estudos recentes, sustentados em documentações variadas, que também se enquadram na esteira da tese proposta por Faria $^{20}$.

O universo cultural nas Minas Gerais setecentista fora caracterizado pelo fenômeno constante do movimento que envolveu corpos e culturas de várias partes do mundo. Uma vez nas Minas, e com a difícil tarefa de "sobreviver em colônia", como se dizia na época, esses povos lançaram mão de adaptações, acomodações e, pari passu, rejeições e impermeabilidades mútuas ${ }^{21}$. Mesclaram-se e construíram formas de pensar e viver que, em última instância, não eram nem europeias, nem indígenas e nem africanas, mas, fruto das complexas dinâmicas de mestiçagens ${ }^{22}$. É possível perceber esses traços quando o objeto de interesse do pesquisador são as organizações familiares.

Tendo em vista essa assertiva, uma vez mais torna-se mister considerar que a noção de "familiaridade" proposta por Raphael Bluteau parece plausível e pode auxiliar na compreensão acerca do que se procura neste estudo: a ampliação do conceito de família no mundo colonial. Essa constatação foi possível porque através da documentação trabalhada transpareceu-se que a população da comarca do Rio das Velhas reuniu práticas familiares pautadas em valores culturais diversificados e que extrapolavam a tênue linha entre as normas e os costumes. Esses, por sua vez, eram criados a partir das realidades vivenciadas no contexto das dinâmicas do cotidiano, o que coloca os aspectos regionais como preponderantes frente à tentativa de se compreender determinadas estruturas socioculturais. Sendo assim, concorda-se com Ana Silvia Volpi Scott quando ela afirma que:

[...] não é novidade encarar que toda a ação social é vista como o resultado de uma constante negociação, manipulação, escolhas, decisões do indivíduo e do grupo familiar, diante de um aparato normativo e regulador que, entretanto, possibilita um grau variado de interpretações e liberdade de ação. (SCOTT, 2015, p. 23)

Através da documentação dos tribunais eclesiásticos, representada como dados na tabela anteriormente reproduzida, bem como considerando a assertiva de Scott, é possível perceber que, na América portuguesa, casamentos nos moldes do que

\footnotetext{
${ }^{20}$ Para a ampliação do conceito de família em estudos recentes, ver: SANTOS, 2018.

${ }^{21}$ Sobre o conceito de "Universo cultural", ver: PAIVA, 2001.

${ }^{22} \mathrm{O}$ conceito de dinâmicas de mestiçagens foi desenvolvido por Eduardo França Paiva em sua obra intitulada "Dar nome ao novo" (PAIVA, 2015).
} 
preconizava o Concílio de Trento $(1545-1563)^{23}$ e o Estado português ${ }^{24}$, dividiram espaços com tipos conjugais multifacetados, a saber, pautados em princípios matrifocais; uniões "presumidas" em que se constatava a estabilidade entre os cônjuges; concubinatos que se apresentavam como escolhas diversas; uniões em que havia ou não filhos; outras nas quais prezava-se pela coabitação e que tinha, neste princípio, a sua característica principal; ou, ainda, arranjos conjugais que assumiram a forma das já definidas pelo historiador Luciano Figueiredo (1997) como "famílias fragmentadas"; dentre outras possibilidades que incluíam, inclusive, a mistura entre todas essas formas mencionadas ${ }^{25}$.Constatando que tais possibilidades conjugais se fizeram presentes nas Minas Gerais setecentistas, especialmente na região em foco, comarca do Rio das Velhas, por si só já torna inviável que se pense a "família" colonial como uma instituição estática e/ou homogênea.

No contexto mineiro, tendo em vista o caleidoscópio sociocultural constituído sobretudo a partir dos descobrimentos das minas de ouro e diamantes em finais do século XVII e início do XVIII, respectivamente, desenvolveram-se tipos de relações familiares que se apresentaram como o resultado das inúmeras práticas de mestiçagens, mas também como resultante delas. Em outras palavras, o que se percebe é que as formas variadas de conjugalidade foram mais um dos mecanismos utilizados por inúmeros homens e mulheres que viveram num espaço e tempo profundamente mesclados e com princípios e práticas de uma sociedade de Antigo Regime, hierarquizada, distinta e desigual.

Essa pluralidade com a qual se revestiram as uniões entre homens e mulheres de "qualidades" e "condições" 26 diferentes podem ser compreendidas tanto enquanto

\footnotetext{
${ }^{23}$ Concílio realizado na cidade de Trento, Itália. Foi convocado pelo papa Paulo III. Seu início data de dezembro de 1545 e seu término, oito anos depois, de 1563. É considerado o concílio mais longo da história da Igreja. Seu principal objetivo era dar respostas imediatas aos avanços que o protestantismo vinha tendo na época. Buscava-se resolver, principalmente, questões referentes às disciplinas e dogmas católicos não definidos em concílios anteriores, bem como ratificar outros tantos outrora definidos, como o sacramento matrimonial, por exemplo, presente já no século XIII durante o IV Concílio de Latrão.

${ }^{24}$ Sobre casamentos na colônia, ver, dentre outros: MACHADO, 2006; LOTT, 2008, GOLDSCHIMIDT, 2004; SAMARA, 1989; SILVA, 1984.

${ }^{25}$ Estudos pioneiros e outros tantos que permitem a ampliação do conhecimento destes casos podem ser encontrados, dentre outros, em FIGUEIREDO, 1997, 1999; LONDOÑO, 1999; FARIA, 2004; SILVA, 1984; GOLDSCHMIDT, 2004; LOPES, 1998; TEIXEIRA, 2004, LOTT, 2008, CERCEAU NETTO, 2008, 2013; SANTOS, 2018.

${ }^{26}$ É importante destacar que todas as vezes que utilizarmos o termo "qualidades", o faremos a partir da noção proposta por Eduardo França Paiva, para quem "as qualidades, portanto, diferenciavam, hierarquizavam e classificavam os indivíduos e os grupos sociais a partir de um conjunto de aspectos (ascendência familiar, proveniência, origem religiosa, traços fenotípicos, tais como a cor de pele, o tipo de cabelo e o formato de nariz e boca), pelo menos quando isso era possível". (PAIVA, 2015, p. 33). No
} 
estratégias de sobrevivência neste mundo hierarquizado e mesclado quanto como o resultado de visões de mundo distintas. Além de permitir, como se sugere neste artigo, a ampliação do próprio sentido de família.

A possibilidade de se compreender os laços familiares enquanto lócus privilegiado para o nascedouro de parte das dinâmicas sociais que ajudaram a definir os contornos da sociedade na América portuguesa só se tornou viável graças aos avanços significativos vivenciados pela produção historiográfica brasileira nos últimos 30/40 anos. Em especial ao pioneirismo da demografia histórica que, através de suas análises quantitativas, condicionaram tipificações variadas sobre a família brasileira e possibilitaram o surgimento de temáticas que hoje permitem uma análise mais abrangente e verticalizada.

\section{Da demografia histórica à possibilidade de ampliação do sentido de família}

O estudo da família para o período colonial brasileiro tem apresentado matizes e contornos diferentes ao longo dos anos entre estudiosos de diversas áreas como historiadores, antropólogos, sociólogos, dentre outros que se debruçaram sobre o tema. Tendo sido favorecido por meio de pesquisas pautadas no método da demografia histórica, alguns trabalhos surgiram a partir das décadas de 1970/1980 e contribuíram para a compreensão da sociedade brasileira sob a ótica das teias e das tramas construídas e vivenciadas no interior dos mais diversificados tipos de arranjos familiares $^{27}$.

$\mathrm{Na}$ realidade, tanto a demografia histórica quanto a história da família constituem campos de investigações independentes e consolidados. Porém, o estreitamento entre ambas as áreas é notável, pois foi graças à metodologia e ao corpus documental introduzidos pela demografia histórica nos estudos referentes às organizações familiares, que se tornou possível avançar nas formas de se analisar e compreender a família em sentido macro.

Os estudos brasileiros surgiram sob a influência do modelo de seriação e quantificação europeia, em especial a partir dos moldes inglês e francês ${ }^{28}$. Ajudaram a

tocante às condições sociojurídicas, nos referimos às três existentes entre a sociedade mineira, a saber, os livres, libertos e escravos.

${ }^{27}$ Ver, dentre outros: MARCÍLIO, 1973, 1974, 1986; SAMARA, 1977, 1980, 1989.

${ }^{28}$ Referimo-nos, aqui, ao chamado Grupo de Cambridge (Cambridge Group for the History of Population and Social Structure) criado, por Peter Laslett, em 1964. No que tange à referência feita à metodologia francesa, destacamos o pioneirismo do método denominado "Reconstituição de Famílias", criado, ainda na década de 1950, pelo demógrafo Louis Henry e o historiador Michel Fleury a partir do Institut 
traçar o perfil da sociedade e de alguns dos aspectos que estiveram presentes em seu processo de formação, tais como, o concubinato, a ilegitimidade, a escravidão, as relações de compadrio, dentre outros fatores. Na verdade, os historiadores demógrafos brasileiros demonstraram que, ao se constatar estruturas organizacionais diversificadas de famílias para a América portuguesa, deviam-se relativizar argumentos que defendiam, mesmo enquanto possibilidades, modelos homogêneos e construídos tão somente sob os princípios considerados legítimos pela Igreja Católica.

Isto é, diversos estudos passaram a considerar as especificidades das regiões em suas conformações familiares; os princípios que constituíram toda a complexidade sociocultural das populações em xeque; as características engendradas como resultado da lógica escravista; e outros fatores que, de uma forma ou de outra, foram vislumbrados tendo como norte, áreas de investigações que abarcavam o estudo sobre as mulheres, a sexualidade, a ilegitimidade, as estruturas dos domicílios, dentre outras ${ }^{29}$.

Vimos anteriormente que tanto a Igreja quanto o Estado, por meio de suas elaborações de documentos com propósitos de moralizar, padronizar, burocratizar, fiscalizar, dentre outros intentos de controle e monitoramento, contribuíram para uma produção de registros que permitem aos estudiosos estudarem as normas e os costumes da população colonial. Isso fora feito, quase que pioneiramente, pelos estudos demográficos a partir dos anos 1950 (e, no caso brasileiro, 1970).

Em especial quando do Concílio de Trento, a Igreja Católica passou a atuar ainda com mais rigor como agente normatizador e moralizador da sociedade colonial. Fazia-se necessário, na visão do Clero, ratificar alguns princípios definidos ainda no IV Concílio de Latrão (1215) e assumir o papel de difusor e fiscalizador de seus preceitos. Uma das maneiras mais eficazes de se tentar o controle da população fora dentro do recinto familiar. Tentando regular o que se poderia fazer com o corpo tanto no espaço público quanto privado, a Igreja buscou padronizar os tipos de registros a serem adotados em celebrações de casamentos, batizados e até mesmo óbitos, como já fora dito.

Produziu-se, assim, principalmente a partir do século XVI, uma enorme quantidade de documentos que permitem, aos historiadores atuais, investigarem

National d'Études Démographiques (INED), em Paris. Uma análise acerca desses grupos de estudos, bem como seu pioneirismo e abordagens pode ser encontrada, dentre outros, em: SCOTT, 2015 e FARIA, 1997.

${ }^{29}$ Estudos com estes perfis, podem ser vistos, dentre outros, em: MARCíliO, 1968, 1974; SAMARA, 1977, 1988, 1989; BACELLAR, 2001. 
aspectos que dizem respeito às formas de casamentos; às diversificadas formatações familiares; aos princípios que remetem a laços de solidariedades desenvolvidos no cotidiano das relações sociais, dentre outros aspectos relevantes e que podem ser considerados quando se tem por objeto de estudo uma sociedade complexa como a que fora a escravista e mestiça comarca do Rio das Velhas.

O ideal para se compreender com maior qualidade as complexas dinâmicas familiares da população mineira, seria realizar pesquisas cujo ponto forte fosse a combinação entre essa documentação eclesiástica com os registros mencionados antes de caráter estatal. Isto é, vislumbrando ganhos qualitativos e quantitativos, as informações extraídas dos registros paroquiais deveriam ser acrescidas, cruzadas e comparadas às obtidas por meio das listas nominativas, por exemplo.

Assim procedendo, enquanto as segundas dariam condições ao pesquisador de mapear configurações domiciliares, os registros de casamentos, batismos e mesmo as que desnudavam as práticas de mancebia, permitiriam que relações de afetividade, companheirismo, solidariedade, além das tipicamente contratuais, fossem descortinadas e oferecessem mais informações sobre costumes de uma sociedade com características de Antigo Regime. Também é válido lembrar que testamentos e inventários postmortem dão subsídios ao mapeamento de fortunas favorecendo o estudo de famílias em seus diferentes sistemas de produção e consumo, e, juntamente com os livros de devassas, apontam traços importantes para se estudar os costumes de uma determinada sociedade dentro de uma época específica, como já fora mencionado.

Para o caso brasileiro, devido às dificuldades referentes às fontes primárias, sobretudo quando remontam datas que antecedem o século XVIII, os estudos demográficos encontraram algumas dificuldades para se investigar o passado de algumas regiões da América portuguesa. Essa é apenas uma das razões pelas quais seus métodos e resultados foram criticados pela produção revisionista na passagem do século XX para o XXI.

Parte considerável do revisionismo historiográfico, amparado por uma abordagem sociocultural, criticou (e, em alguns aspectos, ainda o faz) o método da demografia histórica em função do seu caráter estritamente empirista e quantitativo e trouxera à tona discussões em torno de algumas noções e conceitos outrora relegados ao ostracismo pelos próprios historiadores demógrafos. Em especial a linha interpretativa baseada na noção de patriarcalismo desenvolvida por Gilberto Freyre, em 1933.

Revista Escritas do Tempo - v. 1, n. 3, nov/2019-fev/2020 - p. 247-269 
Freyre, estudando a sociedade brasileira, desenvolveu o conceito de patriarcalismo, que seria generalizado, quase vinte anos depois, nos estudos realizados por Antônio Cândido (1951). Pensou em uma sociedade em que a família pudesse explicar os traços definidores do universo colonial, desde os intentos em prol da colonização até a subjetividade das referências culturais vivenciadas no cotidiano da América portuguesa. Não havia, para Freyre, outros fatores responsáveis pela conformação da sociedade da época que não fosse a família. Assim, destacava:

A família, não o indivíduo, nem tampouco o Estado nem nenhuma companhia de comércio, é desde o século XVI o grande fator colonizador no Brasil, a unidade produtiva, o capital que desbrava o solo, instala as fazendas, compra escravos, bois, ferramentas, a força social que se desdobra em política, constituindo-se na aristocracia colonial mais poderosa da América. (FREYRE, 2006, p. 81)

A noção de família proposta por Freyre está diretamente relacionada ao princípio de liderança exercido pelo homem sobre a casa, as mulheres, os filhos, os escravos e os agregados. Portanto, próxima à definição de Morais Silva. Isso constituía o chamado modelo patriarcal de sociedade. Geralmente pensado para o cotidiano no contexto dos grandes engenhos de açúcar, o modelo freyriano encontrou, ao longo dos anos, resistência entre muitos estudiosos e aquiescência entre outros tantos.

Não é nosso objetivo neste artigo debater a produção que versa a este respeito. É notável o número de estudiosos que já o fizeram e que contribuíram para a compreensão e ampliação do sentido preconizado pelo modelo patriarcalista ${ }^{30}$. Não obstante, alguns pontos merecem ser destacados. Especialmente os que nos permitem entender o papel desempenhado pela demografia histórica na elaboração de uma noção de família.

Na década de 1970, alguns estudiosos brasileiros, lançando mão de metodologias no campo da demografia histórica e através de documentações paroquiais e listas nominativas, abriram a possibilidade para que nos anos seguintes o modelo proposto por Freyre fosse questionado. Essas pesquisas, elaboradas por meio de seriações documentais e inspiradas nos modelos inglês e francês, alargaram a compreensão do sentido referente às formas de constituições e organizações familiares. Isso fora feito tendo em vista as especificidades de cada região.

\footnotetext{
30 A produção historiográfica referente ao modelo de sociedade idealizado por Gilberto Freyre é significativa. Sendo pensado para toda a sociedade colonial, ou levando-se em conta especificidades que caracterizaram as regiões da América portuguesa, são inúmeros os estudos que, ao longo dos anos, se detiveram à temática do "patriarcalismo". Ver, dentre outros: FREYRE, 2006; VAINFAS, 1989; SOUZA, 2004; MAXWUEL, 2005; CORRÊA, 1982.
} 
Ao levar em consideração os regionalismos e suas peculiaridades, a demografia histórica oferecia possibilidades para se questionar a assertiva de Gilberto Freyre. O que não tardou a acontecer. Mariza Corrêa, já no início da década seguinte, publicava a mais severa crítica ao modelo freyriano ao questionar a sua validade para todo o espaço brasileiro ou enquanto princípio explicativo dominante. Indagava a autora:

A chamada "família patriarcal brasileira" era o modo cotidiano de viver a organização familiar no Brasil colonial, compartilhado pela maioria da população, ou é o modelo ideal dominante, vencedor sobre várias alternativas que se propuseram concretamente no decorrer de nossa história? (CORRÊA, 1982, p. 16) ${ }^{31}$

Num contexto em que diversos historiadores brasileiros buscavam seguir os ventos da chamada Nova História francesa e encontrar maneiras de se inserirem no movimento que tentava trazer para os campos da História novos objetos, novas abordagens e novas metodologias, não foram poucas as pesquisas que surgiram e buscaram explicar a sociedade brasileira tendo como base fontes documentais outrora desprezadas e respaldando-se em referências importadas.

A demografia histórica retirava, nesse sentido, o monopólio dos modelos explicativos do Brasil elaborados a partir de abordagens ensaísticas (FARIAS, 1997, p. 241) e formuladas sem o respaldo de uma satisfatória gama documental. Se, por um lado, os historiadores demógrafos contribuíram para perceber as diversificadas constituições familiares, por outro, a forma pela qual o fizeram fora alvo de inúmeras insatisfações. Criticavam-se suas infinitas quantificações elaboradas por vias de tabelas que pouco ou nada ajudavam a explicar a complexidade das organizações familiares em contextos mais regionais e específicos. Principalmente, no interior de uma sociedade que trazia em seu cerne a estrutura escravista e suas incontáveis implicações no cotidiano, incluindo, neste caso, as práticas de mestiçagens.

Essa tomada de consciência na forma de uma leitura crítica sobre as maneiras pelas quais inúmeros historiadores demógrafos liam e utilizavam os dados presentes em diversos documentos levou uma nova geração de estudiosos, a partir dos finais dos anos 1980, principalmente, a lançarem mão de uma abordagem explicativa que procurasse dar mais sentido a toda complexidade existente no interior da América portuguesa.

\footnotetext{
${ }^{31}$ Outras pesquisas foram no esteio de críticas como essa e questionaram o modelo patriarcal da família brasileira. Alguns estudos identificaram o predomínio de unidades domésticas com tamanhos reduzidos para algumas regiões e outras constataram a existência de chefias femininas. Assim procedendo, justificaram ser, o modelo patriarcal de Freyre, insuficiente para se pensar as relações familiares na América portuguesa (DIAS, 1995; SAMARA, 1989, 1991).
} 
Apropriando-se de teorias trazidas de fora e de uma interdisciplinaridade, o movimento revisionista permitiu que as dinâmicas familiares fossem pensadas para além dos números que refletissem apenas "um lado da moeda".

Parte da historiografia brasileira, ao longo dos anos 1980, 1990, 2000, lançou mão de fontes há muito utilizadas pelos historiadores demógrafos e buscou avançar em análises que permitissem compreender não apenas as configurações familiares enquanto estruturas físicas para tipificá-las, mas, sim, suas razões (até mesmo simbólicas) e todo o processo que envolvia as suas conformações. Dentro desse contexto, ocorreu, por parte dos historiadores da família, uma fragmentação de abordagens.

Alguns, como Ronaldo Vainfas (2010) e Silvia Brügger (2007), recuperaram a ideia do patriarcalismo em Freyre justificando-o no seio dos valores cotidianos. Vainfas, um dos pioneiros nesse sentido, ao enfatizar os aspectos valorativos em detrimentos dos estruturais, saía em defesa de Freyre, preconizando:

Se as famílias coloniais eram mais ou menos extensas, se numa dada habitação moravam poucos indivíduos ou dezenas deles, eis um dilema de pouca relevância nos trabalhos de Freyre e Cândido. E quer-nos parecer, ainda, que a maior ou menor concentração de indivíduos, fosse em solares, fosse em casebres, em nada ofuscava o patriarcalismo dominante, a menos que se pretenda que, pelo simples fato de não habitarem a casa-grande, as assim chamadas "famílias alternativas" viviam alheias ao poder e aos valores patriarcais, o que ninguém seria capaz de afirmar, seguramente. (VAINFAS, 2010 , p. 153$)^{32}$

Brügger, assim como Vainfas, defensora dos ideais patriarcais para a sociedade colonial, rechaçava a crítica feita por Mariza Corrêa a Freyre e advertia afirmando que:

A caracterização feita por Freyre, longe estava de atribuir à família patriarcal um predomínio quantitativo na população brasileira. O que ele afirma é a existência de uma sociedade na qual os valores patriarcais são os dominantes, embora não sejam os únicos. (BRÜGGER, 2007, p. 49)

No entanto, outros estudiosos revisionistas sobre a família continuaram relativizando a generalização do patriarcalismo, mesmo enquanto sistema cultural. Estudos como os de Luciano Figueiredo (1997) e Laura de Mello e Souza (2004), negaram o princípio patriarcal para as Minas setecentistas e, assim procedendo, ajudaram a demonstrar que a família patriarcal não foi o único modelo familiar existente na América portuguesa e também não perdurou sozinho onde quer que tenha existido. A ideia de uma "família fragmentada", como levantou Figueiredo, marcada pela presença

32 A primeira edição desta obra foi publicada em 1989, fruto do doutoramento do historiador Ronaldo Vainfas.

Revista Escritas do Tempo - v. 1, n. 3, nov/2019-fev/2020 - p. 247-269 
feminina, muitas vezes de mestiças e africanas, questionava um regime familiar único definido como patriarcal ${ }^{33}$.

Nesse sentido, ampliou-se a compreensão acerca das relações familiares ao abrir possibilidades para se pensar o cotidiano enquanto definidor das mais diversificadas constituições de famílias, envolvendo inúmeros homens e mulheres na colônia. O espaço no qual esses indivíduos se encontravam, bem como seus valores culturais distintos se imbricavam, também passaram a ser considerados quando de análises envolvendo formas afetivas de relacionamentos.

\section{Considerações finais}

Já é lugar comum nos dias atuais, em meio à produção mais recente, que ideias que supõem ter sido a família brasileira, no período colonial, algo homogêneo, estático e ancorado nos valores preconizados pela moral cristã da época, não se sustentam mais. O número de artigos, dissertações, teses e livros que ressaltam as diversificadas maneiras pelas quais se instituíram as relações familiares são notáveis. São refutáveis, igualmente, análises que simplificam o debate em torno das múltiplas configurações familiares reduzindo-as unicamente à tensão entre valores dominantes e tendências marginalizadas.

A historiografia avançou significativamente neste campo de discussão e, dentro de uma vertente da história social da cultura, vem encontrando os trilhos sobre os quais poderá percorrer um caminho rumo à defesa de outras formas de família ${ }^{34}$. Apresenta-se como reflexos de um meio que comportava, simultaneamente, tipos de pensamentos e formas de vivências diversificadas. Nesse sentido, podemos afirmar que na comarca do Rio das Velhas, e, certamente por extensão, em função do que vimos falando até aqui, em toda a capitania mineira, e também em toda a América portuguesa, não existiu somente um modelo de família. Pelo contrário, situadas no contexto de suas lógicas constitutivas e em função de suas necessidades adaptativas, de sobrevivência, afetivas, dentre outras (tantas) possibilidades, podemos afirmar que a pluralização das famílias foi o condicionante das relações sociais que ajudaram a conformar a sociedade colonial.

\footnotetext{
${ }^{33}$ Luciano Figueiredo, em seu livro intitulado "O avesso da memória”, trabalhou com a noção de matrifocalidade e, recentemente, Rangel Cerceau Netto, na esteira destes estudos revisionistas, avança reinterpretando o papel desempenhado pelas mulheres nas Minas Colonial no contexto do que chama de "Famílias Mestiças". Consultar: FIGUEIREDO, 1999 e CERCEAU NETTO, 2017.

${ }^{34}$ PEREIRA, 2004; PRAXEDES, 2003 e 2008; GOLDSCHMIDT, 1998; LONDOÑO, 1999; LOPES, 1998; SANTOS, 2018.
} 
Percebe-se que, além de propor uma nova abordagem a respeito do mundo colonial e de suas mais variadas dinâmicas sociais, a produção historiográfica surgida a partir dos anos 1980/1990 permitiu ao pesquisador investigar novos temas ou revisitar outros tantos outrora problematizados. Isto é, se por um lado o pioneirismo e a relevância dos estudos realizados à luz da história demográfica são irrefutáveis, por outro, algumas das suas limitações foram percebidas, repensadas e tiveram avanços notáveis possibilitados, principalmente, por uma interdisciplinaridade e por novas inquietações intelectuais frutos de teorias e metodologias mais recentes.

\section{Referências}

\section{Arquivo Eclesiástico da Arquidiocese de Mariana - AEAM}

- Livros de Devassas Eclesiásticas, Termos de Culpa. Identificações: fevereiro de 1727 dezembro de 1753; janeiro - março de 1731; outubro de 1733 - janeiro de 1734; julho de 1737 - setembro de 1738; julho de 1748 - janeiro de 1750; Z-5 agosto de 1752 fevereiro de 1756; junho de 1734 - outubro de 1734.

- Livro de Devassas, Testemunhas. Identificações: maio de 1730 - abril de 1731; Z-1 maio - dezembro de 1738; Z-4 junho de 1748 - abril de 1749; Z-8 julho de 1756 fevereiro de 1757; Z-9 julho - setembro de 1759; Z-11 e 12 janeiro de 1767 - maio de 1778; Z-3 novembro de 1747- fevereiro de 1748; Z-4 fevereiro de 1748 - julho de 1748 ; Z-5 agosto de 1756- março de 1757.

\section{Centro de Documentação e Informação da Cúria Metropolitana de Belo Horizonte - CEDIC-BH.}

- Livros de Devassas Eclesiásticas, Termos de Culpa. Identificações: dezembro de 1733 - setembro de 1734.

\section{Fontes impressas}

BLUTEAU, Raphael Padre. Vocabulário português e latino. Coimbra: Colégio das Artes da Companhia de Jesus, 1712.

CAB - CONSTITUIÇÕES PRIMEIRAS DO ARCEBISPADO DA BAHIA, feitas $e$ ordenadas pelo ilustríssimo, e reverendíssimo senhor d. Sebastião Monteiro da Vide, arcebispo do dito arcebispado, e do conselho de Sua Majestade, propostas e aceitas em o sínodo diocesano, que o dito senhor celebrou em 12 de junho do ano de 1707. 3. ed. São Paulo: Tipografia 2 de Dezembro, 1853. (1. ed., Lisboa, 1719; 2. ed. Coimbra, 1720).

FERREIRA, Aurélio Buarque de Holanda. Miniaurélio Século XXI Escolar: o minidicionário da língua portuguesa. Coordenação de edição, Margarida dos Anjos, Marina Baird Ferreira; lexicografia, Margaria dos Anjos et. all. 4 ed. rev. ampliada. Rio de Janeiro: Nova Fronteira, 2001.

SILVA, Antônio de Morais e. Diccionário da língua portuguesa. Recompilado dos vocábulos impressos até agora e nesta segunda edição novamente aumentado e muito acrescentado. Lisboa: Typografia Lacérdina, 1813, 2 vols. 
ALGRANTI, Leila Mezan. Honradas e devotas: mulheres da colônia. Estudo sobre a condição feminina nos conventos e recolhimentos do sudeste do Brasil (750-1822). Rio de Janeiro: José Olympio; Brasília: Edunb, 1993.

ALVES, Débora Cristina. Alianças familiares: estratégias de uma elite de Antigo Regime (Guarapiranga - 1715 a 1790). Dissertação (Mestrado em História). Universidade Federal de Juiz de Fora. Juiz de Fora, 2013.

BACELLAR, Carlos de Almeida Prado. Viver e sobreviver em uma vila colonial. Sorocaba, século XVIII e XIX. São Paulo: Annablume, FAPESP, 2001.

BRÜGGER, Sílvia Maria Jardim. Minas patriarcal: família e sociedade (São João Del Rei - séculos XVIII e XIX). São Paulo: Annablume, 2007.

BURKE, Peter. História e teoria social. Trad. São Paulo: Editora UNESP, 2002.

CÂNDIDO, Antônio. The Brazilian Family. In: SMITH, T. (Org.). Brazil. Portrait of half a continente. New York: Marchant General, 1951.

CERCEAU NETTO, Rangel. Um em casa de outro: concubinato, família e mestiçagem na comarca do Rio das Velhas (1720-1780). São Paulo: Annablume/Belo Horizonte: PPGH/UFMG, 2008.

Entre as formas de se pensar e as maneiras de se viver: a família mestiça e a vida familiar em Minas Gerais colonial. São Paulo: Alameda, 2017.

CORRÊA, Mariza. Repensando a Família Patriarcal Brasileira (Notas para o estudo das formas de organização familiar no Brasil). In: ALMEIDA, Maria Suely Kofes et al. Colcha de Retalhos: Estudo sobre a Família no Brasil. São Paulo: Brasiliense, 1982.

DIAS, Maria Odila Leite da Silva. Quotidiano e Poder em São Paulo no século XIX. São Paulo: Brasiliense, 1995.

FARIA, Sheila de Castro. História da Família e Demografia Histórica. In: CARDOSO, Ciro F. S.; VAINFAS, Ronaldo (Orgs.). Domínios da História: Ensaios de teoria e metodologia. Rio de Janeiro: Campus, 1997, p. 241-258.

Sinhás pretas, damas mercadoras: as pretas minas nas cidades do Rio de Janeiro e São João Del Rey (1700-1850). Tese (Concurso de professor titular). Universidade Federal Fluminense. Niterói, 2004.

FIGUEIREDO, Luciano Raposo de Almeida. Barrocas famílias: vida familiar em Minas Gerais no século XVIII. São Paulo: Hucitec, 1997.

O avesso da memória: cotidiano e trabalho da mulher em Minas Gerais no século XVIII. 2. ed. Rio de Janeiro: José Olympio, 1999.

FREYRE, Gilberto. Casa grande e senzala: formação da família brasileira sob o regime da economia patriarcal. ed. 51. São Paulo: Global, 2006. 
FURTADO, Júnia Ferreira. Chica da Silva e o contratador dos diamantes: o outro lado do mito. São Paulo: Companhia das Letras, 2003.

GOLDSCHMIDT, Eliana Rea. Casamentos mistos: liberdade e escravidão em São Paulo colonial. São Paulo: Annablume, 2004.

GRUZINSKI, Serge. O pensamento mestiço. Trad. Rosa Freira d'Aguiar. São Paulo: Companhia das Letras, 2001.

LONDOÑO, Fernando Torres. A outra família: concubinato, igreja e escândalo na colônia. São Paulo: Loyola, 1999.

LOPES, Eliane Cristina. O revelar do pecado: filhos ilegítimos na São Paulo do século XVIII. São Paulo: Annablume; FAPESP, 1998.

LOTT, Miriam Moura. Na forma do ritual romano: casamento e família em Vila Rica (1804-1839). São Paulo: Annablume/Belo Horizonte: PPGH/UFMG, 2008.

MACHADO, Cacilda. A trama das vontades: negros, pardos e brancos na produção da hierarquia social (São José dos Pinhais - PR, passagem do século XVIII para o XIX). Tese (Doutorado em História). Universidade Federal do Rio de Janeiro. Rio de Janeiro, 2006.

MARCÍLIO, Maria Luiza. Caiçara: terra e população. São Paulo: Paulinas, CEDHAL, 1986.

A cidade de São Paulo: povoamento e população (1750-1850). São Paulo: Pioneira/Edusp, 1973.

Crescimento demográfico e evolução agrária paulista, 1700-1836. Tese (Livre Docência). Universidade de São Paulo. São Paulo, 1974.

MAXWELL, Kenneth. A Devassa da Devassa: A Inconfidência Mineira: Brasil Portugal (1750-1808). Trad. Rio de Janeiro: Paz \& Terra, 1978.

MELLO E SOUZA, Laura de. Norma e conflito: aspectos da História de Minas no século XVIII. Belo Horizonte: Ed. UFMG, 1999.

Desclassificados do ouro: a pobreza mineira no século XVIII. 4. ed. rev. e amp. Rio de Janeiro: Graal, 2004.

OLIVEIRA, Hilton Cesar de. A devassa da vida cotidiana: o delito do concubinato em Minas Gerais setecentista. Dissertação (Mestrado em História). Universidade Estadual de São Paulo. São Paulo, 1999.

PAIVA, Eduardo França. Escravidão e universo cultural na colônia: Minas Gerais, 1716-1789. Belo Horizonte: Editora UFMG, 2001. 
PAIVA, Eduardo França. Escravos e libertos nas Minas Gerais do século XVIII: estratégias de resistência através dos testamentos. 3. ed. São Paulo: Annablume; Belo Horizonte: PPGH/UFMG, 2009. (Coleção Olhares).

Dar nome ao novo: uma história lexical da Ibero-América entre os séculos XVI e XVIII (as dinâmicas de mestiçagens e o mundo do trabalho). Belo Horizonte: Autêntica, 2015.

PEREIRA, Maria Luisa de Castro. O sangue, a palavra e a lei: faces da ilegitimidade em Sabará, 1713-1770. Dissertação (Mestrado em História). Universidade Federal de Minas Gerais. Belo Horizonte, 2004.

PRAXEDES, Vanda Lúcia. A teia e a trama da fragilidade humana: os filhos ilegítimos em Minas Gerais, 1770-1840. Dissertação (Mestrado em História). Universidade Federal de Minas Gerais. Belo Horizonte, 2003.

Segurando as pontas e tecendo tramas: mulheres chefes de domicílio em Minas Gerais, 1770-1880. Tese (Doutorado em História). Universidade Federal de Minas Gerais. Belo Horizonte, 2008.

PRIORE, Mary Del. Ao sul do corpo: condição feminina, maternidade e mentalidade no Brasil Colônia. São Paulo: UNESP, 2009.

SAMARA, Eni de Mesquita. A família brasileira. 3 ed. São Paulo: Brasiliense, 1986.

. As mulheres, o poder e a família. São Paulo, século XIX. São Paulo: Marco Zero \& Secretaria de Estado da Cultura de São Paulo, 1989.

SANTOS, Igor. Famílias plurais: uniões mistas e mestiçagens na comarca de Sabará (1720-1800). Curitiba: Appris, 2018.

Longe de suas esposas, mas ainda em família: o concubinato adulterino como condições para as mestiçagens (Sabará, século XVIII). e-Hum Revista Científica do Departamento de Ciências Humanas, Letras e Artes do Uni-BH. Belo Horizonte, vol. 11, no 2. 2018. pp. 54-65.

SCOTT. Ana Silvia Volpi. A família como objeto de estudo para o Historiador. In: ALTHOFF, Coleta Rinaldi; ELSEN, Ingrid; NITSCHKE, Rosane Gonçalves. (Orgs.). Pesquisando a Família: olhares contemporâneos. Florianópolis: Papa-Livro, 2004, p. 45-54.

As teias que a família tece: uma reflexão sobre o percurso da história da família no Brasil. História: Questões e Debates. Curitiba, n. 51, p. 13-29, jul./dez. 2009. Editora UFPR, 2009.

Entre a "curva" e o "caso": três décadas de história da família no Brasil. In: LIBBY, Douglas Cole; MENESES, José Newton Coelho; FURTADO, Júnia Ferreira; FRANK, Zephyr L. (Orgs.). História da família no Brasil (séculos XVIII, XIX e XX): novas análises e perspectivas. Belo Horizonte: Fino Traço, 2015. pp. 21-49. 
SILVA, Maria Beatriz Nizza da. Sistema de casamento no Brasil colonial. São Paulo: T. A. Queiroz: Editora da Universidade de São Paulo, 1984.

Donas mineiras do período colonial. São Paulo: Editora UNESP, 2017.

TEIXEIRA, Paulo Eduardo. O outro lado da família brasileira. São Paulo: Editora da Unicamp, 2004.

VIANA, Andréa Lopes. Visitações episcopais: processos de devassa ocorridos no Arraial do Tijuco, Capitania de Minas Gerais, 1750. Dissertação (Mestrado Profissional Interdisciplinar em Ciências Humanas). Universidade Federal dos Vales do Jequitinhonha e Mucuri/Faculdade Interdisciplinar em Humanidades. Diamantina, 2017.

VILLALTA, Luiz Carlos. A "torpeza diversificada dos vícios": celibato, concubinato e casamento no mundo dos letrados de Minas Gerais (1748-1801). Dissertação (Mestrado em História). Universidade de São Paulo. São Paulo, 1993.

Artigo recebido em 12 de dezembro de 2019. Aprovado em 11 de fevereiro de 2020. 